\title{
Barbara Honigmann My Life as a Cat | In the Golden Cage
}

Translated by Lauren Beck 



\section{My Life as a Cat}

Summer is hardly a season - it rather resembles another life. It is not yet truly vacation time, since we only go to the sea in August, but this month of July no longer belongs to the working year either. The sky is far too blue, the sunshine seems exaggerated, the kids are all on summer break and just loaf around all day or go to "Phantasialand" with their day camp. The city feels deserted; at least here, in my neighborhood, around the university, everything has died down, and I feel abandoned, like a stranger in my own land.

All this leads to me not having any desire to go to my desk and to work, or at least to pretend to, for how often do I just do my time there, and nothing goes forward, and nothing goes backward either. Absolutely nothing comes to me. In any case, when summer breaks out, all effort feels pretty pointless to me, and my life approximates that of our striped cat. I would like to do nothing more than lie stretched out in the sun like her and when it gets too hot, curl up in the shade until the evening. Only late do we both get a bit friskier, she stops by at her food bowl and catches a couple of flies, and I could go out now and have an ice cream coffee on the terrace with Peter, but even there, we probably would not talk much, even though we usually have so much to discuss. My ambition has shattered, all my plans have evaporated. Write novels? What for? Paint pictures? In this heat? A book? Is there anything new under the sun? The cat thrives like this, after all, she has no plans and no ambition and pursues nothing but her flies and is nonetheless loved and the star of the family.

She lies there purring on my desk, stretched across books, binders, and papers, and will not let me get to work anyway. The pen in my hand is pawed away decisively. She is probably right. She must dream sometimes, and in my head it does not look any different now either, a couple of memories and fantasies are fluttering around. The cat licks her fur, and I will go take a shower now. 


\section{In the Golden Cage}

Our cat named Atze is torn between whether she should remain lying in ambush fighting the snowflakes from under the cover of the laundry rack on the balcony or would rather roast her belly on her spot above the heater after all. I advise her to stay out on the balcony, for how often do we even get snow here anyway, it must have been three years now since we last saw snow on our street. And besides, I tell the cat, I will be going soon, and then I will close the door to the balcony again, and that will be it for your yard exercise this morning. For our cat is not allowed on the street below, because we're afraid that she will get run over or taken away, and because there are no trees or bushes or really anything resembling nature around there anyway, just concrete, asphalt, and cars. We call this decision prudent, what the cat calls it, we do not know. Thus, she lives in a golden cage, and her entire life from beginning to end takes place in our apartment, the view from the windows and the excursions onto the balcony are her only connections to the outside world. I often look at her and ask myself whether she is very unhappy about that and longs for the world behind the apartment door, which does sometimes stand open for a couple of minutes, after all. Of course, we provide her with news from outside, and not just in the form of food from cans and boxes, but rather, when we return from a trip, for instance, we leave our bags or suitcases standing around open and untouched for a couple of days, then she can thoroughly sniff after scents from the unknown and rummage through their innermost contents. We leave a lot of stuff lying around otherwise, too, which makes for cat-friendly territory as well, we have sacrificed all our blankets for cat sleeping spots. Peter built a climbing tree with a scratching post for her, and I brought a corner comber back for her from New York, and she really does use it to thoroughly comb her fur every day. This way, we might find mercy in front of a cat court. But now Atze has already had enough of the silly snowflakes and must, of course, see to it that she doesn't squander her eighteen hours of sleep. She pads over to me, looks at me, and clearly wants to say, "Man, your worries and Rothschild's money!" 